\title{
Tunable Boc Modification of Lignin and Its Impact on Microbial Degradation Rate
}

\author{
Liuqun Gu, ${ }^{1,2 *}$, Meifeng Wang, ${ }^{2,3}+\mathrm{Hui} \mathrm{Li}^{2}{ }^{2}$ Kai Ni Teh, ${ }^{1} \mathrm{Yiqun}^{\mathrm{Li}}{ }^{3 *}$ and Ye Liu ${ }^{1 *}$ \\ ${ }^{1}$ Institute of Materials Research and Engineering (IMRE), Agency for Science, Technology and Research (A- \\ STAR); 4 Fusionopolis Way, Innovis Building, 138635, Singapore \\ ${ }^{2}$ Department of Biomedical Engineering, Jinan University; \#601, Huangpudadaoxi, Guangzhou, China \\ ${ }^{3}$ Department of Chemistry, Jinan University; \#601, Huangpudadaoxi, Guangzhou, China \\ : Both authors contributed equally \\ *Corresponding author: E-mail: guliuqun@yahoo.com or tlyq@jnu.edu.cn or ye-liu@imre.a-star.edu.sg
}

\begin{abstract}
A new type of modified lignin, lignin-p-Boc, was obtained through reaction with di-tert-butyl dicarbonate $\left(\mathrm{Boc}_{2} \mathrm{O}\right)$ in aqueous media catalyzed by 4-dimethylaminopyridine (DMAP). Boc modification occurred regardless of type of lignin, was tunable, and proceeded well in recovering lignin at high purity from sodium lignosulfonate (a common byproduct from pulping industry; lignin content: $60 \%$ ). Lignin-p-BOC was demonstrated as a potential reactive filler in green plastic and as a potential crosslinker in design of bioresorbable composite polymeric implants. Furthermore, the effects of the modification on the breakdown rate of alkali lignin by microbes was investigated, and the results showed that the modification substantially decreases the breakdown rate. The tunable Boc modification process was designed via a system thinking, including availability of raw lignin, economical/green modification, potentiality of drop-in-change to current thermoplastic processing, modification impact on microbial degradability/disposed environment at the end of use life; hence the holistic consideration makes this alternative method for upgrade of technical lignins very practical for future industrial application. Via forming "easily breakable covalent bonds" with thermopolymers, Lignin-p-BOCs are also promising to play an important role as both excellent binders via "random match" and reductants in transforming linear plastic waste into circular plastics.

Keywords: Lignin, System thinking, Reactive filler, Boc modification, Microbial degradation.
\end{abstract}

\section{INTRODUCTION}

Lignin is one of most abundant biopolymers and the most with rich aromatic components in nature. However, for utilization in industry it is much lagging behind than other biopolymers such as cellulose [1,2]. One of main reasons is due to its random designed structure by nature; and lignin structure can be different after separation as a waste from the same bio-resource via different processes in pulping plants [3], which adds more difficulty for quality control in its utilization [3,4]. Not surprisingly, the employment of lignin as macromolecule filler attracted a lot of attention because the negative effect of its less defined structure could be minimized. Especially the use of lignin as reinforcement in biodegradable thermoplastic was extensively explored due to the recent public concern to environmental impact of conventional plastic [5].

Chemically lignin is composed of significant amount of phenolic and aliphatic hydroxyl groups as well as some acidic functional groups, and hence it is very polar. Direct use of (technical) lignin would lead to incompatible or immiscible composites when mixing with non-polar thermoplastic [6,7]. A common approach to increase the hydrophobicity is to modify lignin by masking the free hydroxyls (Scheme 1). The most widely used method is to protect hydroxyl groups of lignin with anhydrides [8,9], silyl reagents [10] or fatty acids [11-14] forming new ester bonds which are less polar (Scheme 1). The advantage is simple and cost can be very cheap; another method is to modify lignin with "graft to" or "graft from" strategies forming star polymers [6,7]. For example: lignin-gPLA [15], rosin-lignin copolymer [16,17] and hydroxypropyl lignin (hydropropyl group with 
certain length) $[18,19]$. The advantage is longer hydrophobic chain; however it can be a difficulty to remove short-chain polymers after grafting and resulted cost might hamper the potential application. General method for modification of lignin in low cost, particularly via a system thinking of whole value chain of targeted applications along with lignin drop-in-change, is still highly desirable for future lignin utilization in large scale.

Recently, tosylated lignin was synthesized in an aqueous medium in the absence of any organic solvent; it is more reactive than unmodified lignin and shows potential for several applications [20]. Inspired by this work, here we develop a new practical method to modify lignin with di-tert-butyl dicarbonate $\left(\mathrm{Boc}_{2} \mathrm{O}\right)$ without using any organic solvents (Scheme 1). The degree of modification can be tuned by adjusting loading of catalyst and amount of $\mathrm{Boc}_{2} \mathrm{O}$ used. The $\mathrm{Boc}$ modified lignin shows more reactive than unmodified lignin, which is promising for design of new green composite via reactive blending with thermopolyesters newly forming O-Boc/cyclic carbonates group on modified lignin. In addition, under optimized conditions various aromatic hydroxyl groups could all be converted into single syringyl type ones in basic aqueous solution which increases the regularity of lignin in structure. This method was also demonstrated to be very efficient in recovering lignin in high purity from industrial lignosulfonate lignin (lignin content: 60\%). Further evaluation of the microbial (white rot fungus $P$. chrysosporium) breakdown rate with both alkali lignin and alkali lignin-p-BOC and results indicated that the presence of Boc groups in lignin substantially decreased the rate of degradation.

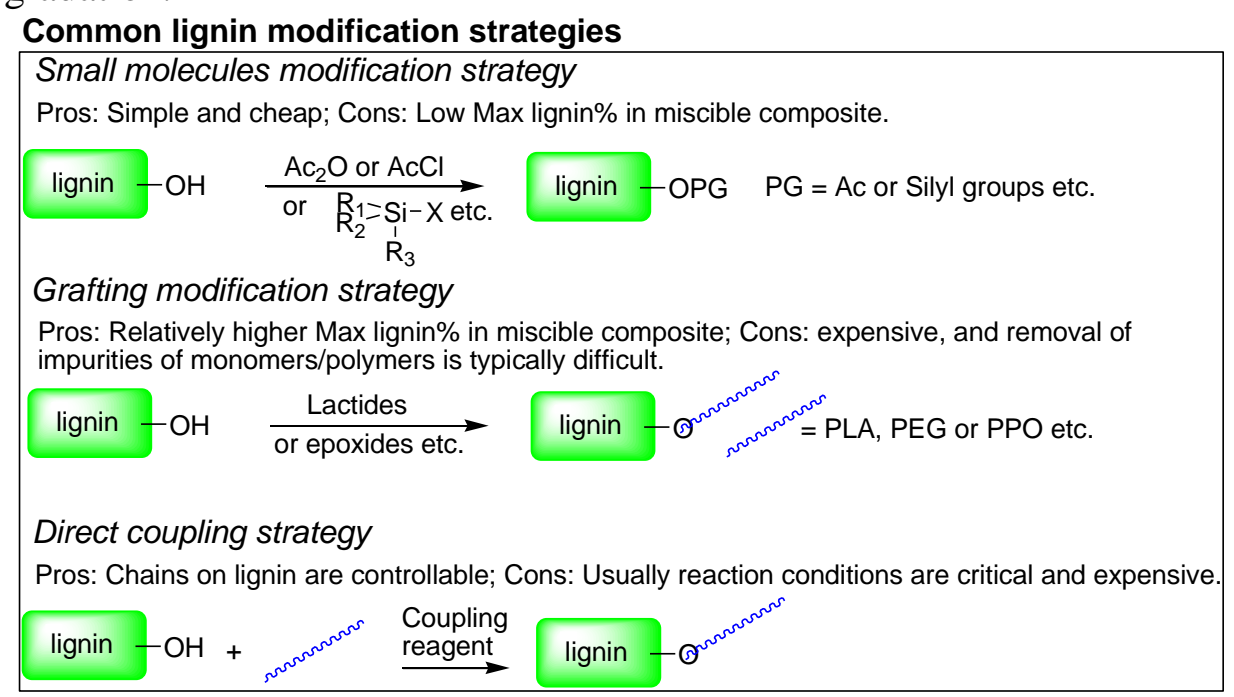

Our new reactive modification strategy

Pros: cheap and chains on lignin are controllable; flammable byproducts might be removed
during reactive extrusion.
lignin $-\mathrm{OH} \frac{\mathrm{Cat} .}{(\mathrm{Boc})_{2} \mathrm{O}}$ lignin $-\mathrm{OBoc} \frac{\text { Thermopolymers }}{\text { Reactive extrusion }}$ lignin

Scheme 1. Common lignin modification strategies and our new reactive one

Di-tert-butyl dicarbonate $\left(\mathrm{Boc}_{2} \mathrm{O}\right)$ is well known as a reagent for protection of amines and alcohols in organic synthesis in the presence of base catalyst [21-23]. In addition, it is also used as a dehydrating agent in reaction with carboxylic acids [24]. A recent revisited reaction of alcohols with $\mathrm{Boc}_{2} \mathrm{O}$ in the presence of 4-dimethylaminopyridine (DMAP) indicated that the pKa of the alcohols strongly affect formation of products (symmetrical carbonates or O-Boc) and reaction rate; More acidic alcohol reacts faster with $\mathrm{Boc}_{2} \mathrm{O}$ [21]. Inspired by this finding, we envisaged that the acidic hydroxyl (phenolic) and carboxylic acid groups which are of much importance to the polar property of lignin could be easily protected with $\mathrm{Boc}_{2} \mathrm{O}$ (Scheme 2). Furthermore, 1,2-diols or 1,3diols might possibly be converted into cyclic carbonates according to the literature (Scheme 2) $[22,25]$. In a result, the modified lignin would be more hydrophobic. 

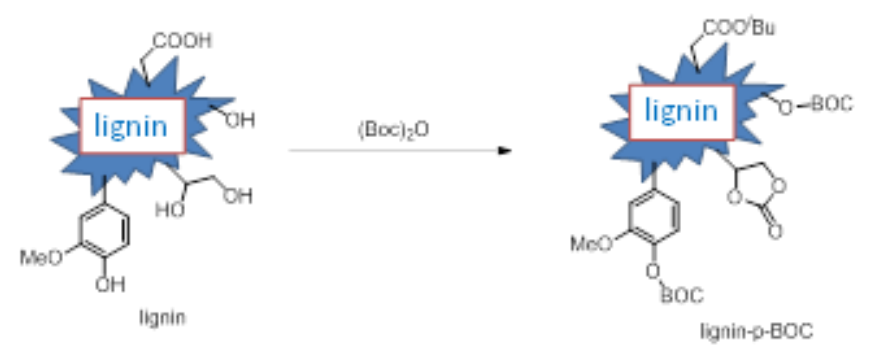

Scheme 2. Structure of lignin and a postulated modified structure of lignin

\section{MATERIALS AND METHODS}

Alkaline lignin and sulfite lignin were purchased from Tokyo Chemical Industry Co., Ltd. (TCI), Singapore and Shanghai. The raw sulfite lignin (purity: around 60\%) was purchased from Shaanxi New Leader Enterprise; Di-tert-butyl dicarbonate $\left(\mathrm{Boc}_{2} \mathrm{O}\right)$ was purchased from Sigma-Aldrich and Scientific Resource Pte Ltd (Alfa-Aesar) as well as Aladdin, Shanghai. All other common chemicals were purchased either from Sigma-Aldrich (Singapore), Aladdin or Macklin, China. Double beam TU-1901 UV-visible spectrophotometer was from Beijing Persee General Instrument Ltd. The white rot fungus $P$. chrysosporium (ATCC 24725) was bought from Guangdong Culture Collection Center.

\subsection{Characterization of Lignin}

All lignin samples were freeze-dried under reduced pressure before use for FTIR, NMR analysis. For reactions with $\mathrm{Boc}_{2} \mathrm{O}$, lignin was used without any pretreatment from bottle. All NMR samples were measured at room temperature.

31P NMR Spectroscopy. All experiments were carried out on a JEOL $500 \mathrm{MHz}$ or a Bruker 400 $\mathrm{MHz}$ spectrometer. Quantitive ${ }^{31} \mathrm{P}$ NMR Spectra of all lignin was obtained according to published method. Alkaline lignin, sulfite lignin and all lignin-p-BOCs were freeze-dried under reduced pressure for 2 days before measurement. General method: To a dry vial $(1 \mathrm{~mL})$ with $30 \mathrm{mg}$ lignin sample was added with a solvent mixture of anhydrous pyridine and deuterated chloroform $(0.5 \mathrm{~mL}$ in $1.6 / 1 \mathrm{~V} / \mathrm{V}$ ), subsequently phosphitylating reagent (2-chloro-4,4,5,5-tetramethyl-1,3,2dioxaphospholane (TMDP), $50 \mu \mathrm{L})$, cylcohexanol $(100 \mu \mathrm{L}, 10.85 \mathrm{mg}$ in a solvent mixture of anhydrous pyridine and deuterated chloroform in $1.6 / 1 \mathrm{~V} / \mathrm{V}$ ) as an internal standard, and chromium (III) acetylacetonate solution $(100 \mu \mathrm{L}, 5.0 \mathrm{mg}$ in a solvent mixture of anhydrous pyridine and deuterated chloroform in 1.6/1 V/V) as a relaxation reagent. Finally the solution was made up to 1 $\mathrm{mL}$ with solvent mixture of anhydrous pyridine and deuterated chloroform (in 1.6/1 V/V), then the vial was sealed tightly and the solution was shaken for 2 hours to ensure thorough mixing. This final mixture was transferred into a dry NMR tube for subsequent analysis. ${ }^{31} \mathrm{P}$ NMR chemical shifts were referenced with respect to water signal at 132.2 or cyclohexanol signal at 145.2. Peak of phosphitylating reagent TMDP was at 176.0. The content of hydroxyl groups for phosphitylating reagent was obtained by integration of the following spectral regions: aliphatic hydroxyls (150.3 $145.3 \mathrm{ppm})$, condensed phenolic units $(144.6-141.2 \mathrm{ppm})$, syringyl phenolic units (143.3 - 142.0 ppm), guaiacyl phenolic hydroxyls (140.5 -138.6 ppm), p-hydroxyphenolic units (138.5 - 137.3 ppm) and carboxylic acids (135.9 - 134.0 ppm).

${ }^{1} \mathbf{H}$ NMR Spectroscopy. Quantitive ${ }^{1} \mathrm{H}$ NMR Spectra of all lignin was obtained with pentafluorobenzaldehyde as an internal standard. All experiments were carried out on a JEOL 500 $\mathrm{MHz}$ or Bruker $300 \mathrm{MHz}$ for 1024 scans. $40 \mathrm{mg}$ Pentafluorobenzaldehyde $(0.2 \mathrm{mmol})$ was added into $10 \mathrm{~mL} d_{6}$-DMSO in a vial. The solution was shaken for a thorough mixing and then kept for use (Standard A). To a vial ( $1 \mathrm{~mL})$ with $10 \mathrm{mg}$ lignin sample was added Standard A $(0.5 \mathrm{~mL})$, then the solution was shaken for 2 hours to ensure thorough mixing. It was transferred into a NMR tube for subsequent analysis.

Boc Protection of Lignin. General procedure A: A mixture of $2 \mathrm{~N} \mathrm{NaOH}(5 \mathrm{~mL})$, alkali lignin $(1 \mathrm{~g})$ and $\mathrm{Boc}_{2} \mathrm{O}(2.5 \mathrm{~mL}$ or other amount as shown in tables) with a stirring bar in a $20 \mathrm{~mL}$ vial was placed into an ice-water bath, then DMAP (339 $\mathrm{mg}$ or $100 \mathrm{mg}$ ) was added slowly and the mixture was warmed to room temperature after 20 mins. The reaction continued to be stirred at room temperature for 3 hours or 1 day. After then, $2 \mathrm{~N} \mathrm{HCl}$ was added drop by drop to adjust the $\mathrm{pH}$ 
value to about 2 . The modified lignin was isolated by centrifugation and subsequent washed with deionized water $(3 \times 20 \mathrm{~mL})$. The isolated product was freeze-dried under reduced pressure to give a dry sample for characterization. General procedure B: A mixture of $\mathrm{MeCN}(5 \mathrm{~mL})$, alkali lignin $(1 \mathrm{~g})$ and $\mathrm{Boc}_{2} \mathrm{O}(2.5 \mathrm{~mL})$ with a stirring bar in a $20 \mathrm{~mL}$ vial was placed into an ice-water bath, then DMAP (339 mg) was added and the mixture was warmed to room temperature after 20 mins. The reaction continued to be stirred at room temperature for 1 day. The organic solvent was removed by air flowing and the latter workup procedure was same to that of the above General procedure A.

Demonstration as a potential reactive filler by simple mixing of lignin-p-BOC and polyethylene glycol. A mixture of lignin-p-BOC $(0.25 \mathrm{~g})$ and polyethylene glycol $(\mathrm{Mw}=2000$ or 400) $(1 \mathrm{~mL})$ was stirred at $60^{\circ} \mathrm{C}$ for 1 hour; the heterogeneous mixture became homogeneous after reaction. Then the mixture was cooled to room temperature and was precipitated in hexane/ethyl acetate solution. Pale yellow powder was obtained as a product lignin-p-PEG in $0.197 \mathrm{~g}$ (PEG 400: $0.185 \mathrm{~g}$ ) (molar ratio 1/1 to total hydroxyls) and further dried in vaccum for hours before NMR characterization. ${ }^{1} \mathrm{HNMR}$ data of both products indicated PEG reacted with lignin-p-BOC and considerate amount of PEG chains were attached onto lignin core successfully.

Preparation of hydropropyl alkaline lignin. The preparation procedure was according to reported procedure [19]. ${ }^{31} \mathrm{P}$ NMR result indicated that almost all the aromatic hydroxyls were masked with hydropropyl groups (total aliphatic $\mathrm{OH}: 3.80 \mathrm{mmol} / \mathrm{g}$ ).

Demonstration as a potential reactive filler with BOC protection of hydropropyl alkaline lignin. Modification reactions in acetonitrile or $\mathrm{NaOH}$ solution were similar to General procedure $A$ and General procedure $B$ with $\mathrm{Boc}_{2} \mathrm{O}$ (molar ratio $1 / 1$ to total hydroxyls) in the presence of 10 wt $\%$ DMAP for 1 day.

FT-IR Analysis. Fourier transform infrared spectra was obtained with powdered solid lignin on $\mathrm{KBr}$ disks. Spectra were collected from 4000 to 400 (or 600 ) $\mathrm{cm}^{-1}$ with 16 cans. A typical BOC modified lignin: -OH, $3000-3700 \mathrm{~cm}^{-1}$; C-H stretch, 2976 and $2940 \mathrm{~cm}^{-1}$; C=C stretch, $2050-$ $2070 \mathrm{~cm}^{-1} ; \mathrm{C}=\mathrm{O}$ (bicarbonate) stretch, 1755, 1650 (conjugated) $\mathrm{cm}^{-1} ; \mathrm{C}=\mathrm{C}$ (aromatic) bending and ring puckering, 1566 and $1511 \mathrm{~cm}^{-1}$; C-O vibration, $1278,1257,1215,1145,1038 \mathrm{~cm}^{-1}$.

\subsection{General methods for microbial degradation of alkali lignin and lignin-p-BOC 2}

A new batch of BOC modified lignin was synthesized for microbial degradation testing according to the same procedure in preparation of lignin-p-BOC 2. Many microorganisms are capable of degrading lignin and one of the best characterized species is white-rot fungi. This strain we selected was Phanerochaete chrysosporium ( $P$. chrysosporium). The culture was maintained on malt agar slants at $4^{\circ} \mathrm{C}$, and then transferred to malt agar plates and cultured at $39^{\circ} \mathrm{C}$ for 7 days. The spores on the agar were scrapped and suspended in the sterile water. The spore concentration was determined by measuring absorbance at $650 \mathrm{~nm}$ and adjusted to $5.0 \times 10^{6}$ spores $/ \mathrm{ml}$. Lignin degradation was studied in $50 \mathrm{~mL}$ Kirk's nitrogen limitation cultures without veratryl alcohol adding in 200-ml Erlenmeyer flasks. Lignin was added as a solution in $1 \mathrm{~mL}$ of $10 \%$ DMSO to give a concentration of $1 \mathrm{~g} / \mathrm{L} .5 \mathrm{~mL}$ of spore suspension was added to each flask, and the $\mathrm{pH}$ was adjusted to 4.5 with $\mathrm{H}_{3} \mathrm{PO}_{4}$. Lignin degradation was carried out at $39^{\circ} \mathrm{C}$ for 18 days and flushed with oxygen every day. Control groups containing no spore were incubated like spore-containing cultures. All experiments were carried out in triplicates. Absorption of solution of lignin was measured with double beam UV-visible spectrophotometer. A portion $(0.5 \mathrm{~mL})$ was taken out from the culture samples every day and then sonicated for $30 \mathrm{~s} ; 4.5 \mathrm{~mL}$ of $0.55 \%$ (W/V) $\mathrm{NaOH}$ was added to the culture in order to precipitate mycelia and protein. Then the mixture was centrifuged and the supernatant was diluted to proper concentration and measured at $280 \mathrm{~nm}$.

\section{RESULTS AND DISCUSSION}

\subsection{Effect of solvent and loading of DMAP on total hydroxyls of alkali lignin}

Initially a reaction of alkali lignin and $\mathrm{Boc}_{2} \mathrm{O}$ in acetonitrile with catalytic amount of DMAP was performed at room temperature for 1 day (Table 1). Boc modification of lignin occurred as expected smoothly by comparison of ${ }^{1} \mathrm{H}$ NMR/FT-IR spectra of commercial lignin and lignin-pBOC after modification [26]. Quantitive ${ }^{31} \mathrm{P}$ NMR of purified lignin-p-BOC 1 indicated after modification the content of the total free hydroxyls and carboxylic acids dropped to $41 \%$ (2.53 
$\mathrm{mmol} / \mathrm{g}$, entry 1, Table 1) of that of commercial alkali lignin $(6.12 \mathrm{mmol} / \mathrm{g}$, Figure 1). Since poor solubility of lignin in acetonitrile was observed, a reaction in $\mathrm{NaOH}$ solution was also performed; remarkable increase on reaction efficiency was achieved and the units of total free $\mathrm{OH}$ of lignin-pBOC 2 were reduced to $10 \%(0.63 \mathrm{mmol} / \mathrm{g}$, entry 2, Table 1) of the original one. Reaction rate for Boc protection of lignin was very fast at room temperature and in 3 hours the content of free $\mathrm{OH}$ for lignin-p-BOC 3 was comparable with lignin-p-BOC 2 that achieved in 1 day [11\% $(0.67 \mathrm{mmol} / \mathrm{g})$ VS $10 \%(0.63 \mathrm{mmol} / \mathrm{g})$ of original one, entries 2 and 3, Table 1$]$.

A control reaction of lignin and $\mathrm{Boc}_{2} \mathrm{O}$ in the absence of DMAP was also examined, and a result indicated $\mathrm{NaOH}$ solution could also slightly promote Boc protection of lignin, although in a much lower efficiency on masking of aliphatic hydroxyls (units of free aliphatic hydroxyls: 66\% (1.39 $\mathrm{mmol} / \mathrm{g}) \mathrm{VS} 16 \%(0.33 \mathrm{mmol} / \mathrm{g})$ of original one, entries 2 and 4, Table 1). In concern of cost, reactions with low amount of $\mathrm{Boc}_{2} \mathrm{O}$ and DMAP were also examined, comparable concentration of residual hydroxyls (18\% VS 16\%, entries 2 and 5, Table 1) for lignin-p-BOCs was observed, however a lower yield was achieved with equivalent amount of $\mathrm{Boc}_{2} \mathrm{O}$. The reaction proceeded well with less DMAP (10 wt $\%$ ) as a catalyst albeit total free hydroxyls on new product slightly increased (17\% VS 10\%, entries 2 and 6, Table 1).

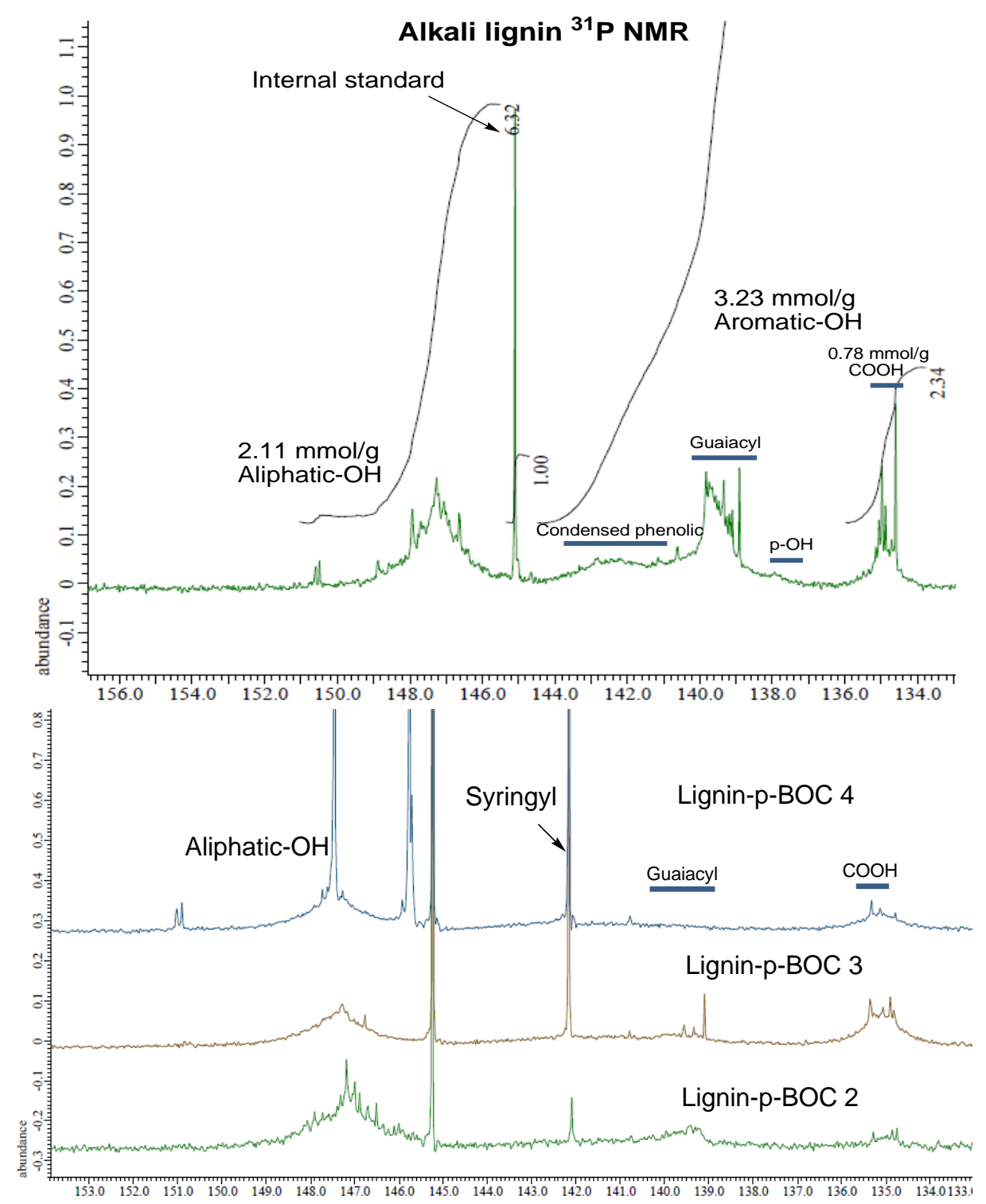

Figure 1. Quantitative ${ }^{31} \mathrm{P}$ NMR Spectra and signal assignment of commercial alkali lignin and alkali lignin-p-BOC 2 - 4 in $\mathrm{CDCl}_{3} /$ pyridine.

Table 1. Boc modification of alkali lignin with $\mathrm{Boc}_{2} \mathrm{O}^{a}$ 


\begin{tabular}{|c|c|c|c|c|c|c|c|c|}
\hline $\begin{array}{l}\text { Ent } \\
\text { ries }\end{array}$ & Solvent & $\begin{array}{l}(\text { Boc })_{2} \\
\text { O } \\
(\mathbf{m L})\end{array}$ & $\begin{array}{l}\text { DMAP } \\
\text { (mg) }\end{array}$ & $\begin{array}{l}\text { Lignin-p- } \\
\text { BOC (g) } \\
\text { (Sample } \\
\text { number) }\end{array}$ & $\begin{array}{l}\text { Aliphatic } \\
\text { OH } \\
(\mathbf{m m o l} / \mathrm{g}) \\
(\%)^{\mathrm{c}}\end{array}$ & $\begin{array}{l}\text { Aromati } \\
\text { c OH } \\
(\mathbf{m m o l} / \mathrm{g}) \\
(\%)^{\mathrm{c}}\end{array}$ & $\begin{array}{l}\text { Carboxylic } \\
\text { acid } \\
(\mathbf{m m o l} / \mathrm{g}) \\
(\%)^{\mathrm{c}}\end{array}$ & $\begin{array}{l}\text { Total } \\
\text { free } O H \\
\text { and acid } \\
(\mathrm{mmol} / \mathrm{g}) \\
(\%)^{\mathrm{c}}\end{array}$ \\
\hline 1 & $\mathrm{MeCN}$ & 2.5 & 339 & 0.79 (1) & $0.75(64)$ & $1.50(54)$ & $0.28(64)$ & $2.53(59)$ \\
\hline 2 & $\mathrm{NaOH}$ aq. & 2.5 & 339 & $1.08(2)$ & $0.33(84)$ & $0.30(91)$ & $0.32(59)$ & $0.95(84)$ \\
\hline $3^{b}$ & $\mathrm{NaOH}$ aq. & 2.5 & 339 & $1.13(3)$ & $0.46(78)$ & $0.21(93)$ & $0.35(55)$ & $1.02(83)$ \\
\hline 4 & $\mathrm{NaOH}$ aq. & 2.5 & 0 & $1.08(4)$ & $1.39(34)$ & $0.38(88)$ & $0.18(83)$ & $1.95(68)$ \\
\hline 5 & $\mathrm{NaOH}$ aq. & 1.4 & 339 & $0.88(5)$ & $0.37(82)$ & $0.51(84)$ & $0.24(77)$ & $1.12(82)$ \\
\hline 6 & $\mathrm{NaOH}$ aq. & 2.5 & 100 & $1.21(6)$ & $0.53(75)$ & $0.51(84)$ & $0.31(60)$ & $1.35(78)$ \\
\hline 7 & $\mathrm{NaOH}$ aq. & 0.5 & 50 & $0.97(\mathbf{1 3})$ & $0.64(70)$ & $1.27(61)$ & $0.36(54)$ & $2.27(63)$ \\
\hline 8 & - & - & - & $\begin{array}{l}\text { Alkali } \\
\text { lignin }\end{array}$ & 2.11 & 3.23 & 0.78 & 6.12 \\
\hline
\end{tabular}

$a$ Reaction conditions: DMAP (339 mg) was added into a mixture of $2 \mathrm{~N} \mathrm{NaOH}(5 \mathrm{~mL})$, alkali lignin $(1 \mathrm{~g})$ and $\mathrm{Boc}_{2} \mathrm{O}(2.5 \mathrm{~mL})$ with a stirring bar in a $20 \mathrm{~mL}$ vial. The solution was stirred at room temperature (rt) for $1 \mathrm{~d} ; b$ : The reaction was performed at $\mathrm{rt}$ for 3 hours; c: Conversion percent of hydroxyls or acid.

\subsection{Effect of solvent and loading of DMAP on total hydroxyls of sulfite lignin}

In current market, lignin byproducts (lignosulfonate) from sulfite process for chemical pulping of wood are dominant although Kraft lignin is projected to be the most in a decade [3,27]. Hence to develop an economic method to utilize sodium lignosulfonate is in great need considering application potential. Boc modification of sodium lignosulfonate was also optimized similarly and generally similar trend was observed (Table 2). However, generally lower yields were achieved probably because of their better solubility in water. Interestingly, with this method, lignin-p-BOC can be recovered easily on water from industrial sodium lignosulfonate lignin (lignin purity: 60\%) [28], probably because the inside base promoted the reaction (Entry 7, Table 2). This process not only combines the modification and pre-purification in one pot, but also reuses the waste impurity [29] as a base.

\subsection{Effect of reaction conditions on selective masking of lignin}

The presence of catalytic DMAP accelerated Boc modification of aliphatic $\mathrm{OH}$ groups (units of free aliphatic hydroxyls: $16 \%(0.33 \mathrm{mmol} / \mathrm{g}) \mathrm{VS} 66 \%(1.39 \mathrm{mmol} / \mathrm{g})$ of original one, entries 2 and 4 , Table 1), meanwhile $\mathrm{NaOH}$ showed its promotion preference on modification of aromatic $\mathrm{OH}$ groups (units of free aliphatic hydroxyls: $66 \%(1.39 \mathrm{mmol} / \mathrm{g}) \mathrm{VS}$ aromatic hydroxyls $12 \%(0.38$ $\mathrm{mmol} / \mathrm{g}$ ) of original one, entry 4, Table 1 and Figure 1). The aromatic hydroxyls were masked in faster rate probably because they are more acidic and deprotonation process by base catalyst is the determined step. Interestingly, all the aromatic hydroxyls could either be protected by Boc or be converted into syringyl $\mathrm{OH}$ when the Boc modification reaction was performed in $\mathrm{NaOH}$ solution for 1 day in the absence of DMAP (lignin-p-BOCs 4 and 10, Figure 2), which is not observed in reported methods for modification of lignin; more syringyl $\mathrm{OHs}$ were probably generated by a $\mathrm{HCl}$ promoted Friedel-Crafts alkylation reaction of guaiacyl part (2-substituted phenolic moiety) with $\mathrm{Boc}_{2} \mathrm{O}$ (a well-known chemistry under similar conditions) during workup stage with $\mathrm{HCl}$ solution. The existence of DMAP had negative effect on this selective transformation especially when reaction time was prolonged, although it benefited Boc protection of aliphatic $\mathrm{OH}$. 

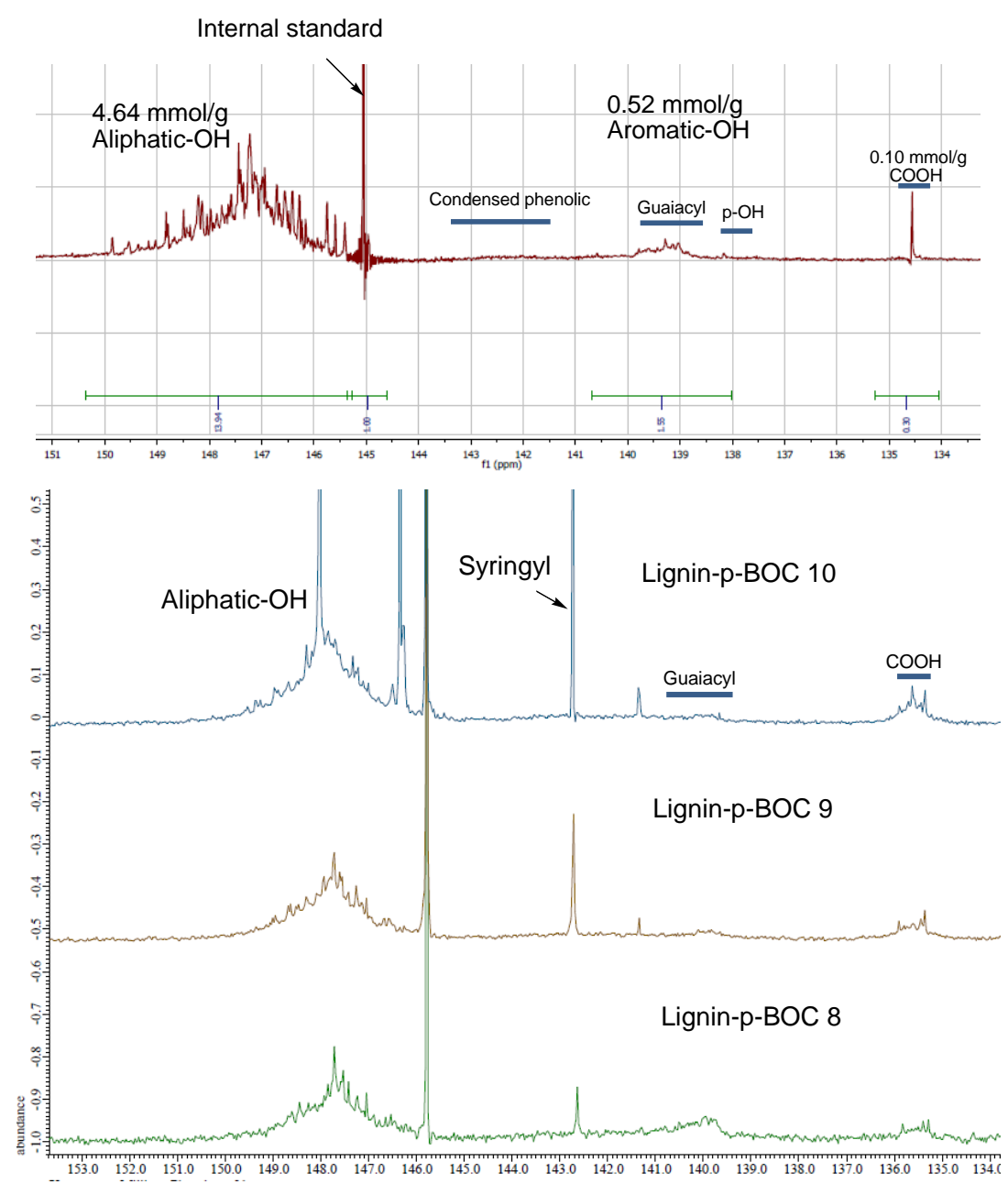

Figure 2. Quantitative ${ }^{31} \mathrm{P}$ NMR spectra and signal assignment of commercial sulfite lignin and sulfite lignin-p-BOC 8 - 10 in $\mathrm{CDCl}_{3} /$ pyridine.

\subsection{Reactivity after Boc modification}

The units of Boc groups calculated based on quantitative ${ }^{1} \mathrm{H}$ NMR of lignin-p-BOC were not always consistent with the units of decreased free hydroxyls calculated based on ${ }^{31} \mathrm{P} N \mathrm{NR}$, which indicated further reactions including $\mathrm{O}-\mathrm{Boc}$ reactions with free $\mathrm{OH}$ into cyclic carbonates or $\mathrm{Boc}_{2} \mathrm{O}$ promoted lactones formation might occur as expected $[24,25]$. The fact that units of O-Boc in lignin-p-BOC 2 (in 1 day) were less compared to those of lignin-p-BOC 3 (in 3 hours) from quantitative ${ }^{1} \mathrm{H}$ NMR; it suggested that longer reaction benefited further reactions of O-Boc with other free hydroxyls, resulting to less free hydroxyl. To achieve a structurally compatible polymer blends based on lignin usually required a pretreatment of lignin by grafting short chains on isolated lignin [30,31]. A simple reactive lignin without grafting group can potentially increase the highest content of lignin for compatible polymer blends. To be reactive filler in new thermoplastic composites, O-Boc groups on lignin-p-BOC are expected to be still reactive with other free nucleophilic groups (such as aliphatic OHs, NHs) from thermoplastic during extrusion. In order to demonstrate the possible reactivity, hydropropyl alkaline lignin [32] was selected as a model substrate because it has excellent solubility in common deuterium solvents $\left(\mathrm{CDCl}_{3} /\right.$ pyridine or $d_{6^{-}}$ DMSO) and newly formed long chain hydropropyl groups can also act as free nucleophilic OHs similar to those from thermoplastics.

Table 2. BOC modification of sulfite lignin with (Boc) $)_{2} \mathrm{O} .{ }^{a}$

\begin{tabular}{lcccccccc}
\hline $\begin{array}{l}\text { Ent } \\
\text { ries }\end{array}$ & Solvent & $\begin{array}{c}\text { (Boc) } \\
\text { O }\end{array}$ & $\begin{array}{c}\text { DMA } \\
\text { P }\end{array}$ & $\begin{array}{c}\text { Lignin-p- } \\
\text { BOC }(\mathrm{g})\end{array}$ & $\begin{array}{c}\text { Aliphatic } \\
\text { OH } \\
(\mathrm{mmol} / \mathrm{g})\end{array}$ & $\begin{array}{c}\text { Aromatic } \\
\mathbf{O H} \\
(\mathrm{mmol} / \mathrm{g})\end{array}$ & $\begin{array}{c}\text { Carboxy } \\
\text { lic acid } \\
(\mathrm{mmol} / \mathrm{g})\end{array}$ & $\begin{array}{c}\text { Total free } \\
\text { OH and acid } \\
(\mathrm{mmol} / \mathrm{g})\end{array}$ \\
\hline
\end{tabular}




\begin{tabular}{ccccccccc}
\hline & & $(\mathbf{m L})$ & $\mathbf{( m g )}$ & $(\mathbf{N u m b e r})$ & $\mathbf{( \%}^{\mathbf{d}}$ & $\mathbf{( \% )}^{\mathbf{d}}$ & $\mathbf{( \% )}^{\mathbf{d}}$ & $\mathbf{( \% )}^{\mathbf{d}}$ \\
\hline 1 & $\mathrm{MeCN}$ & 2.5 & 339 & $0.23(\mathbf{7})$ & $0.79(83)$ & $0.43(17)$ & 0.12 & $1.33(75)$ \\
2 & $\mathrm{NaOH}$ aq. & 2.5 & 339 & $0.48(\mathbf{8})$ & $0.55(88)$ & $0.19(63)$ & $0.03(70)$ & $0.77(85)$ \\
$3^{\mathrm{b}}$ & $\mathrm{NaOH}$ aq. & 2.5 & 339 & $0.57(\mathbf{9})$ & $0.88(81)$ & $0.17(67)$ & 0.12 & $1.17(78)$ \\
4 & $\mathrm{NaOH}$ aq. & 2.5 & 0 & $0.19(\mathbf{1 0})$ & $1.98(57)$ & $0.26(50)$ & 0.13 & $2.37(55)$ \\
5 & $\mathrm{NaOH}$ aq. & 1.2 & 339 & $0.57(\mathbf{1 1})$ & $0.69(85)$ & $0.27(48)$ & 0.10 & $1.06(80)$ \\
6 & $\mathrm{NaOH}$ aq. & 2.5 & 100 & $0.47(\mathbf{1 2})$ & $0.95(80)$ & $0.31(40)$ & 0.09 & $1.35(74)$ \\
$7^{\mathrm{c}}$ & $\mathrm{NaOH}$ aq. & 1.5 & 100 & $0.62(\mathbf{1 4})$ & $1.06(77)$ & $0.44(15)$ & 0.45 & $1.95(63)$ \\
8 & - & - & - & Sulfite & 4.64 & 0.52 & 0.10 & 5.26
\end{tabular}

$a$ Reaction conditions: DMAP (339 mg) was added into a mixture of $2 \mathrm{~N} \mathrm{NaOH}(5 \mathrm{~mL})$, sulfite lignin $(1 \mathrm{~g})$ and $\mathrm{Boc}_{2} \mathrm{O}(2.5 \mathrm{~mL})$ with a stirring bar in a $20 \mathrm{~mL}$ vial. The solution was stirred at $\mathrm{rt}$ temperature for $1 \mathrm{~d} ; b$ : The reaction was performed at $\mathrm{rt}$ for $3 \mathrm{hrs}$; $c$ : Reaction conditions: DMAP $(100 \mathrm{mg})$ was added into a mixture of DI water $(5 \mathrm{~mL})$, industrial sulfite lignin (purity $60 \%, 2 \mathrm{~g})$ and $\mathrm{Boc}_{2} \mathrm{O}(1.5 \mathrm{~mL})$ with a stirring bar in a $20 \mathrm{~mL}$ vial; The solution was stirred at $\mathrm{rt}$ temperature for $3 \mathrm{hrs}$; $d$ : Conversion percent of hydroxyls or acid.

In order to prove that reactive extrusion with lignin-p-BOC is possible, polyethylene glycol (PEG) was chosen for simple mixing with lignin-p-BOC at $60{ }^{\circ} \mathrm{C}$ for 1 hour in the absence of any other reagent. The new PEG peaks on ${ }^{1} \mathrm{HNMR}$ spectra of products with $\mathrm{PEG}_{2000}$ and $\mathrm{PEG}_{400}$ indicated that further reactions occurred as expected and PEG chains were introduced onto lignin core successfully (Figure 3). This expected further reactivity can be potentially applied in extrusion process for green composites as well, and might be easily extended to synthesis of various biocompatible materials for biomedical application [33] like bioresorbable composite polymeric implants [34] et.al, in which lignin-p-BOCs play both roles of crosslinkers and fillers.

Reactions in acetonitrile and in $\mathrm{NaOH}$ solution with $\mathrm{Boc}_{2} \mathrm{O}$ (molar ratio 1/1 to total hydroxyls) in the presence of $10 \mathrm{wt} \%$ DMAP were parallel performed for 1 day. Isolated Boc modified product from reaction in acetonitrile showed no signal of free hydroxyl or carboxylic acid on ${ }^{31} \mathrm{P}$ NMR spectra surprisingly. Samples became significantly insoluble in $\mathrm{CDCl}_{3} /$ pyridine or $d_{6}$-DMSO after modification, which indicated that intermolecular carbonation involved with O-Boc and other free $\mathrm{OH}$ groups occurred as expected, forming larger polymers with intense cross-linked structure. Interestingly, the degree of intermolecular reaction remarkably decreased when reaction was performed in aqueous solution $(\mathrm{NaOH})$ and Boc modified hydropropyl alkaline lignin (aliphatic hydroxyls: $1.33 \mathrm{mmol} / \mathrm{g}$ ) was fully soluble in $\mathrm{CDCl}_{3} /$ pyridine or $d_{6}$-DMSO, which showed that the future reactive extrusion might also be tunable by controlling the moisture content (details see SI). For utilization of lignin, its random structure designed by nature is considered as a big disadvantage even after modification; meanwhile components of plastic waste composite are well known to be random in foreseen future in which two types of thermopolymers (aliphatic rich type and aromatic rich type) prefer to interact with their own kind, leading to poor performance of new composite. Common solution by using a single or several commercial binders (compatilibizers) would likely not work well because of random components in waste composite; lignin-p-Boc is prospected to be an ideal binder due to its random structure by nature and many reactive O-Boc functional groups being able to covalently connect with thermopolymers in plastic waste. A random match [35] of lignin-p-BOC and plastic waste composite enhanced by covalent bonding initialized by O-BOCs may lead to a significant improvement on performance of new upgraded composite. In addition, 
lignin moiety as well-known antioxidant [36] in the new waste composite is expected to decrease degradation of plastic waste during mechanical recycling as well as future repeated uses [37]. Removal of degradable lignin moiety under mild condition via breaking carbonate bond (formed by O-Boc with terminal functional group of thermopolymers) and addition of a new batch of lignin-pBoc would make the quality of new composite in the next repeated use more consistent. In general, the three advantages of "random match", "easily breakable covalent bonding" and "reducing degradation" by using lignin-p-BOC as a binder/anti-oxidant in upcycling of plastic waste might contribute to a profitable circular plastics economy in the future (Scheme 3).

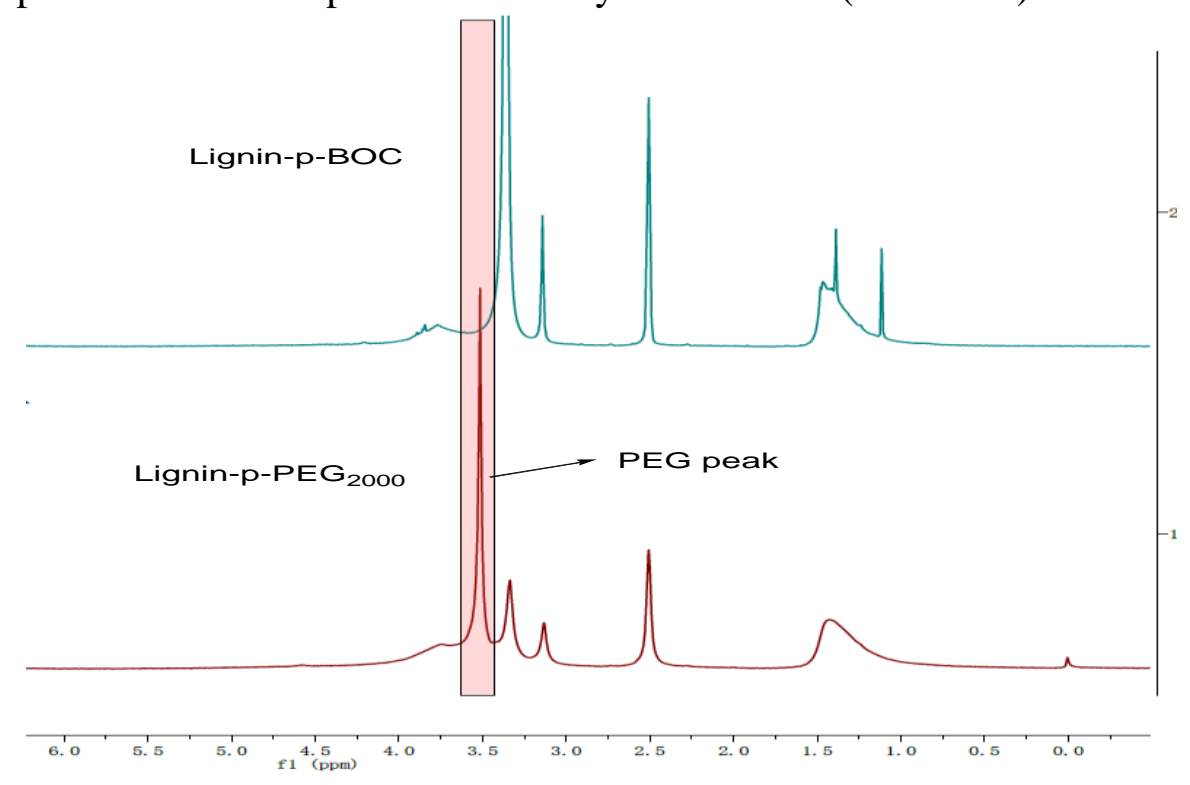

Figure 3. Comparison of lignin-p-BOC with further reacted product lignin-p-PEG 2000 .

\section{Potential application of lignin-p-BOC \\ Lignin-p-BOC as a reactive filler for lignin-based biodegradable composite}

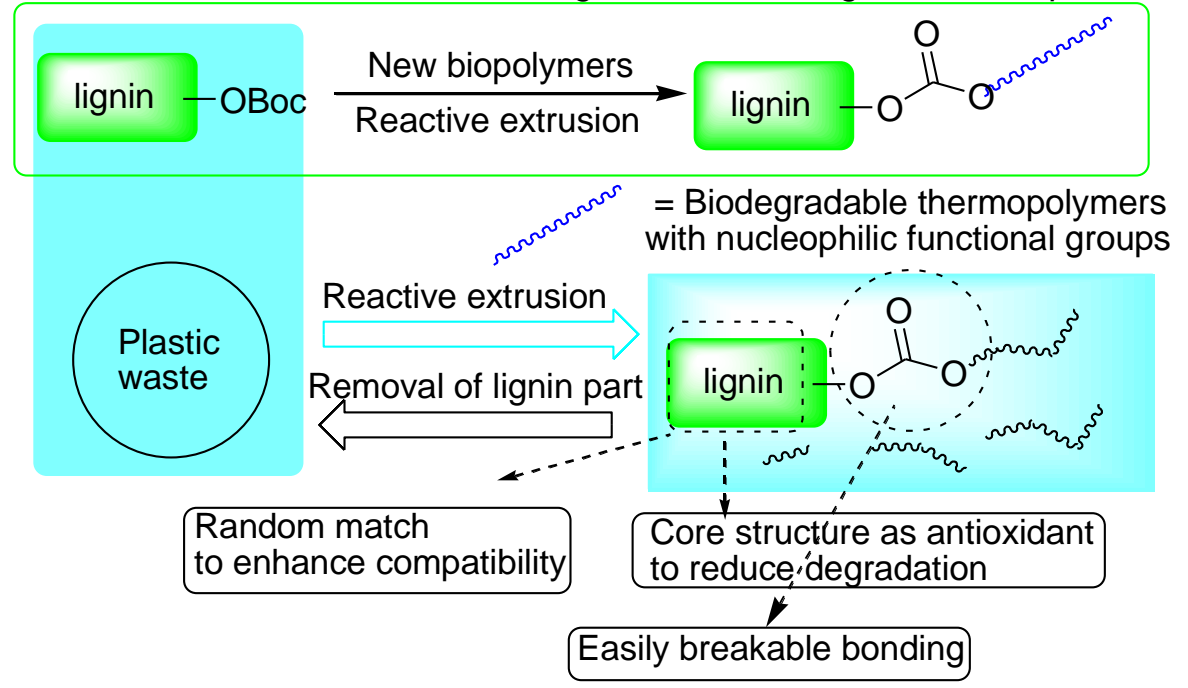

Note: 1. Carbonate bond is well known to be breakable under mild condition; 2. A subsequent washing with water or alkaline water could remove lignin part easily.

Scheme 3. Potential applications of lignin-p-BOCs

\subsection{Investigation on microbial degradation}


Concerning Boc modification might have effect on degradation of lignin and with which fully biodegradable single-used plastics [38], we evaluated the microbial (white rot fungus P. chrysosporium) breakdown rate of both alkali lignin and alkali lignin-p-BOC in parallel according to literature [39]. The presence of Boc groups in lignin obviously decreased the rate of degradation by white rot fungus $P$. chrysosporium within 18 days (Figure 4), which is consistent with proposed enzyme breakdown mechanism initiated from hydroxyl parts [40]. This finding is of much importance to future design of "green plastics" with modified lignin as a major component in balancing the stability in storage and biodegradability under landfill condition.

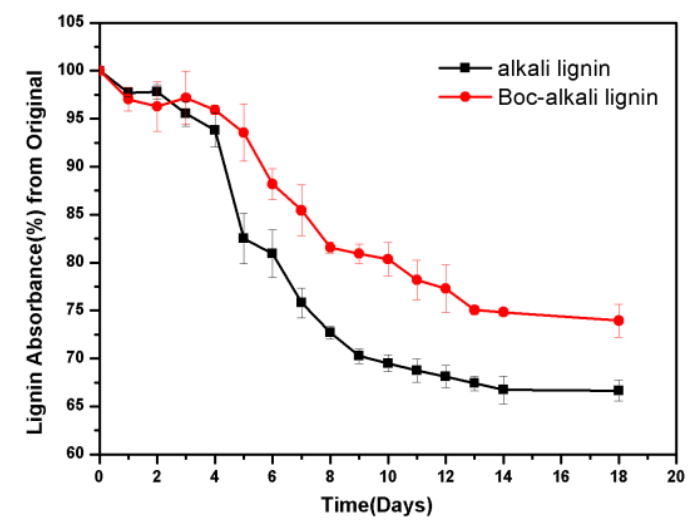

Figure 4. Absorption change of alkali lignin and Boc-alkali lignin at 280nm.

\section{CONCLUSIONS}

In summary, a new type Boc modified lignin was synthesized under mild conditions with $\mathrm{Boc}_{2} \mathrm{O}$ and the modification was generally tunable on the degree of Boc protection and preference on the different hydroxyls by slight change of reaction conditions. Simple optimization indicated that Boc modification occurred more efficiently in aqueous medium in the absence of any organic solvent, and both types of commercial lignin (alkaline and lignosulfonate) were examined. This method demonstrated to be very efficient in recovering lignin in high purity from industrial lignosulfonate lignin (lignin content: 60\%). This process not only combines the modification and pre-purification in one pot, but also reuses the waste impurity (in industrial lignosulfonate lignin) as a base. The modified lignin-p-BOC also shows potential as a reactive filler for new composites. The reactive potentiality of $\mathrm{O}$-Boc group with aliphatic $\mathrm{OH}$ was demonstrated in Boc modification of hydropropyl alkaline lignin. Evaluation of the microbial breakdown rate of both alkali lignin and alkali lignin-p-BOC in parallel indicated that the presence of Boc groups in lignin substantially decreased the degradation rate. This new modification process after a system thinking of both lignin industry and targeted applications, would likely increase its potency as an alternative practical method for upgrade of technical lignins via a drop-in-change. [41] The three advantages of "random match", "easily breakable covalent bonding" and "reducing degradation" by using lignin-p-BOC as a binder/anti-oxidant in upcycling of plastic waste might contribute to a profitable circular plastics economy in the future.

Supporting Information. Data and spectrum of ${ }^{1} \mathrm{H}$ NMR, FT-IR and ${ }^{31} \mathrm{P}$ NMR of lignin-p-BOC prepared under different conditions as well as experimental details in microbial degradation of alkali lignin and alkali lignin-p-BOC see are available free of charge in Supporting Information.

\section{AUTHOR INFORMATION}

ORCID: Liuqun Gu: 0000-0002-4254-6824

Notes

The authors declare no competing financial interest 


\section{ACKNOWLEDGMENT}

We acknowledge the funding support (Biomass-to-Chemicals) to Y. Liu from the Science and Engineering Research Council (SERC) of the Agency for Science, Technology and Research (A*STAR), Singapore and a startup funding from Jinan University to L. Gu (No: 88015155 and 88016607).

\section{References}

1. Mülhaupt, R., 2013. Green polymer chemistry and biobased plastics: dreams and reality. Macromol. Chem. Phys., 214 (2), 159-174.

2. Bruijnincx, P.C.A., Rinaldi, R., Weckhuysen, B. M., 2015. Unlocking the potential of a sleeping giant: lignins as sustainable raw materials for renewable fuels, chemicals and materials. Green. Chem., 17 (11), 4860-4861.

3. Culebras, M., Sanchis, M.J., Beaucamp, A., Carsí, M., Kandola, B.K., Horrocks, A.R., Panzetti, G., Birkinshawf, C. and Collins, M.N., 2018 Understanding the thermal and dielectric response of organosolv and modified kraft lignin as a carbon fibre precursor Green. Chem., 20, 4461-4472.

4. Laurichesse, S., Avérous, L., 2014. Chemical modification of lignins: Towards biobased polymers. Prog. Polym. Sci., 39 (7), 1266-1290.

5. Saito, T., Brown, R.H., Hunt, M.A., Pickel, D.L., Pickel, J.M., Messman, J.M., Baker, F.S., Keller, M., Naskar, A.K., 2012. Turning renewable resources into value-added polymer: development of lignin-based thermoplastic. Green. Chem., 14 (12), 3295-3303.

6. Duval, A., Lawoko, M., 2014. A review on lignin-based polymeric, micro- and nano-structured materials. React. Funct. Polym., 85, 78-96.

7. Sen, S., Patil, S., Argyropoulos, D.S., 2015. Thermal properties of lignin in copolymers, blends, and composites: a review. Green. Chem., 17 (11), 4862-4887.

8. Li, Y., Sarkanen, S., 2005. Miscible blends of kraft lignin derivatives with low-Tg polymers. Macromolecules., 38 (6), 2296-2306.

9. Guo, Z.-X., Gandini, A., Pla, F., 1992. Polyesters from lignin. 1. The reaction of kraft lignin with dicarboxylic acid chlorides. Polym. Int., 27 (1), 17-22.

10. Sailaja, R.R.N., Deepthi, M.V., 2010. Mechanical and thermal properties of compatibilized composites of polyethylene and esterified lignin. Mater. Des., 31 (9), 4369-4379.

11. Firdaus, M., Meier, M.A.R., 2013. Renewable co-polymers derived from vanillin and fatty acid derivatives. Eur. Polym. J., 49 (1), 156-166.

12. Thiebaud, S., Borredon, M.E., 1995. Solvent-free wood esterification with fatty acid chlorides. Bioresour. Technol., 52 (2), 169-173.

13. Thiebaud, S., Borredon, M.E., Baziard, G., Senocq, F., 1997. Properties of wood esterified by fatty acid chlorides. Bioresour. Technol., 59 (2 \& 3), 103-107.

14. Tamminen, T., Ropponen, T., Hult, E., Poppius-Levlin, K., 2014. US patent: 20140243511.

15. Chung, Y.L., Olsson, J.V., Li, R.J., Frank, C.W., Waymouth, R.M., Billington, S.L., Sattely, E.S., 2013. A renewable lignin-lactide copolymer and application in biobased composites. ACS Sustainable Chem. Eng., 1 (10), 1231-1238.

16. Wang, J.-F., Yao, K.-J., Korich, A.L., Li, S.-G., Ma, S.-G., Ploehn, H.J., Lovine, P.M., Wang, C.-P., Chu, F.-X., Tang, C.-B., 2011. Combining renewable gum rosin and lignin: towards hydrophobic polymer composites by controlled polymerization. J. Polym. Sci. Part A: Polym. Chem., 49 (17), 3728-3738.

17. Thielemans, W., Can, E., Morye, S.S., Wool, R.P., 2002. Novel applications of lignin in composite materials. J. Appl. Polym. Sci., 83 (2), 323-331.

18. Pavier, C., Gandini, A., 2000. Oxypropylation of sugar beet pulp. 2. Separation of the grafted pulp from the propylene oxide homopolymer. Carbohydr. Polym., 42 (1), 13-17. 
19. Sadeghifar, H., Cui, C., Argyropoulos, D.S., 2012. Toward thermoplastic lignin polymers. part 1. selective masking of phenolic hydroxyl groups in kraft lignins via methylation and oxypropylation chemistries. Ind. Eng. Chem. Res., 51 (51), 16713-16720.

20. Diop, A., Awada, H., Zerrouki, R., Daneault, C., Montplaisir, D., 2014. Tosylation and characterization of lignin in water. Ind. Eng. Chem. Res. 2014, 53 (43), 16771-16776.

21. Basel, Y., Hassner, A., 2000. Di-tert-butyl dicarbonate and 4-(dimethylamino)pyridine revisited: their reactions with amines and alcohols. J. Org. Chem., 65 (20), 6368-6380.

22. Chankeshwara, S.V., Chebolu, R., Chakraborti, A.K., 2008. Organocatalytic methods for chemoselective O-tert-butoxycarbonylation of phenols and their regeneration from the O-t-Boc derivatives. J. Org. Chem., 73 (21), 8615-8618.

23. Cheraiet, Z., Hessainia, S., Ouarna, S., Berredjem, M., Aouf, N.-E., 2013. A simple and ecosustainable method for the O-Boc protection/deprotection of various phenolic structures under water-mediated/catalyst-free conditions. Green Chem. Lett. Rev., 6 (3), 211-216.

24. Pozdnev, V.F., 1995. Activation of carboxylic acids by pyrocarbonates. Application of di-tertbutyl pyrocarbonate as condensing reagent in the synthesis of amides of protected amino acids and peptides. Tetrahedron Lett., 36 (39), 7115-7118.

25. Nagarajan, M., Kumar, V.S., Rao, B.V., 1997. Di-tert-butyl pyrocarbonate mediated synthesis of macrocyclic lactones from $\omega$-hydroxy acids. Tetrahedron Lett., 38 (33), 5835-5838.

26. The details in identifying different functional groups of lignin-p-BOC see Supporting Information.

27. Wang, Y.-Y., Chen, Y., Sarkanen, S., 2015. Path to plastics composed of ligninsulphonates (lignosulfonates). Green. Chem., 17 (11), 5069-5078.

28. Lignin product data was from Alibaba website.

29. The raw sodium lignosulfonate (purity: around 60\%) was purchased from Shaanxi New Leader Enterprise Ltd, China; the major impurities are sodium oxide $\left(\mathrm{Na}_{2} \mathrm{O}, 16 \%\right)$ and volatile acid (8\%) according to a product report from the supplier.

30. Nge, T.T., Tobimatsu, Y., Takahashi, S., Takata, E., Yamamura, M., Miyagawa, Y., Ikeda, T., Umezawa, T., and Yamada, T., 2018. Isolation and characterization of polyethylene glycol (PEG)-modified glycol lignin via PEG solvolysis of softwood biomass in a large-scale batch reactor. ACS Sustainable Chem. Eng., 6, 7841-7848.

31. Culebras, M., Beaucamp, A., Wang, Y., Clauss, M.M., Frank, E., and Collins, M.N., 2018. Biobased structturally compatible polymer blends based on lignin and thermoplastic elastomer polyurethane as carbon fiber precursor. ACS Sustainable Chem. Eng., 6, 8816-8825.

32. Hydropropyl alkaline lignin was prepared according to reported literature (reference [19]). ${ }^{31} \mathrm{P}$ NMR result indicated that almost all the aromatic hydroxyls were masked with hydropropyl groups (total alphatic $\mathrm{OH}: 3.80 \mathrm{mmol} / \mathrm{g}$ ).

33. Kai, D., Zhang, K., Jiang, L., Wong, H.Z., Li, Z., Zhang, Z., and Loh, X.J., 2017. Sustainable and antioxidant lignin-polyester copolymers and nanofibers for potential healthcare applications ACS Sustainable Chem. Eng., 5(7), 6016-6025.

34. Sharma, U., Concagh, D., Core, L., Kuang, Y., You, C., Pham, Q., Zugates, G., Bunsold, R, Webber, S., Merlo, J., Langer, R., Whitesides, G.M., and Palasis, U., 2018. The development of bioresorbable composite polymeric implants with high mechanical strength Nat. Mater., 17 (1), 96103.

35. "Random match" concept with lignin was initially proposed by Gu, L., Potential of lignin use in plastic recycling: a random match. news on bio-based Europe, July 30, 2019.

36. A recent review with lignin as an antioxidant see: Galkin, M., 2021. From stabilization strategies to tailor-made lignin macromolecules and oligomers for materials. Curr. Opin. Green Sustain., 28: 100438.

37. Degrading of polymer chains in mechanical recycling and subsequent quality consistent challenge in recycling of plastic waste was reviewed: Schyns, Z. O. G., Shaver, M. P., 2021. Mechanical recycling of packaging plastics: a review. Macromol. Rapid Commun., 42, 2000415. 
38. A recent report on marine pollution by plastic waste inputs from land sees: Jambeck, J.R., Geyer, R., Wilcox, C., Siegler, T.R., Perryman, M., Andrady, A., Narayan, R., Law, K.L., 2015. Plastic waste inputs from land into the ocean. Science, 347 (6223), 768-771.

39. Ulmer, D.C., Leisola, M.S.A., Schmidt, B.H., Fiechter, A., 1983. Rapid degradation of isolated lignins by Phanerochaete chrysosporium. Appl. Environ. Microbiol., 45 (6), 1795-1801.

40. Bugg, T.D.H., Ahmad, M., Hardiman, E.M., Rahmanpour, R., 2011. Pathways for degradation of lignin in bacteria and fungi. Nat. Prod. Rep., 28 (12), 1883-1896.

41. A more comprehensive system thinking on benefits and advantages of Boc modified lignin sees a pre-recorded presentation video in ACS Fall 2020 National Meeting \& Exposition (Cell Division) in San Francisco, CA, August 20, 2020 (virtual) link: https://doi.org/10.1021/scimeetings.0c06672. 